Ion? The question is easily auswered. All these minerals have once been embedded in the granitic gneiss which is the principal rock of the region" (and which weathers readily). . . . "In weathering, the difficultly decomposable precious stones have not been attacked, or attacked only to a limited extent: they have there fore retained their original form and hardness. When in the course of thounds of years, streams of water have flowed over course of thousands of year's, streams of water have flowed ove part changed into a fine mud, and as such washed away, while part changed into a fine mud, and as such washed away, while
the hard gems have only been inconsiderably rounded and little diminished in size. The current of water, therefore, has not been able to wash them far away from the place where they were originally embedded in the rock; and we now find them collected in the gravel-bed, resting for the most part on the fundamental rock which the stream has left behind, and which afterwards, when the water has changed its course, has been a cain covered by new layers of mud, clay, and and. O O all the kind of stones whe layers of mud, clay, and sai are usod for ormanents, there are both noble and connon varic ties, without there being any perceptible difference in their chem ical composition. The most skilful chemist would have difficulty in finding, in their chemical composition, the least difference be tween colundum and sapphire or ruby; between common bery and emerald; between the precious and common topaz; between the hyacinth and the common zircon; between precious and common spinel: and every minomalogist knows that there aro innumerable intermediate the betwe innume lissimilar, though absolitely identical ininerals wh are so dissimilar, though absolutely identical in composition. This gave the old naturalists oceasion to speak of ripe and un ripe precious stones. They said that in order to ripen precions stones the heat of the south was required. 'L'his transference of well-known circumstances from the vegetable to the minera kingdom is certainly without justitication. It points, however, to a remarkable and hitherto anexplained circumstance; namely, that the occurrence of precious stones is, with few exceptions, confined to southern reorions. Another remarkable fact in connection with precious stones is, that most of those that come connection with precious stones is, that most of those that grains in sand-beds. True jewel-mines are few, unproductive, and easily exhausted. From this, one would be inclined to sup pose that $\mathrm{f}$ recious stones actually undergo an ennobling process in the warm soil of the south."

To the writer of this note, it seems more reasonable to suppose that the greater abundance of noble gems in southern climates should be attributed to the more active and thorough-going disintegration which occurs in those regions, and to the consequent - com paratively speaking - enormous acemmulation and concentration of the precious minerals, as above suggested. Other things might be far from being equal, and yet the chance of finding a stone of price be greater in a heap of ten thousand rough jewels than in a collection which contains but a few score.

Bussey Institution.

F. H. STORER.

The November aurora in California.

Auroras are exceedingly rare phenomena in southern California; yet we had the pleasure of witnessing one Nov. 17, at which time a great electric storm raged over North America and Europe. The photographic traces during the time from Nov. 10 to Nov. 20 are very interesting; as they have preserved a perfect record of the twitchings and jerkings, large and small, fast and slow, to which the magnets were subjected during this time.

A slight shock of earthquake was reported here on Jan. 23 , about 5.20 P.M. I was on the street, and did not feel it; and so far as I can detect no harm was done at the observatory. MArcus BAKER.

Los Angeles, Cal., Jan. 26.

\section{TRYON'S CONCHOLOGY.}

Structural and systematic conchology: an introrluction to the study of the Mollusca; by GEORGE W. TRYon, JR. Vol. I. Philadelphia, the author. 1882. $8+312$ p., cuts, $22 \mathrm{pl}$. $8^{\circ}$.

WE have received the first volume of $\mathrm{Mr}$. 'Tryon's new work (to be completed in three volumes), intended as an introduction to the study of the mollusks. 'This portion consists of sume general considerations, a description of the anatomy, habits, and economy, distribution in space and time, notes on nomenclature, classification and collection, of mollusks. Assistance in paleontological matters has been rendered by Prof. Angelo Heilprin. The work is well printed and bound; but the plates, though not so bad as in the "Manual' of the same author, contain mostly inferior renderings from old and familiar figures, pioduced by processes which cannot be made to yield really good results. The map is very badly drawn, and besides this, through 'overlaying,' resulting from folding and inferior or excessive ink, has become nearly illegible. Mr. 'Tryon frankly disclaims authorship for his compilation, which is derived almost wholly from Woodward's well-known 'Manual,' and the earlier parts of Dr. Paul Fischer's 'Manuel de conchyliologie,' now in process of publication. Since both these works are accessible at a total price less than that of the first volume of Mr. 'Tryon's book, it is not clear' why the latter should exist. Perhaps the future volumes will explain.

Meanwhile we do not feel that any very warm welcome should be extended to a work of compilation so destitute of perspective as this. Though not what the author would have made it had Lovèn's work on the dentition of mollusks appeared ten years earlier, Woodward's book is nevertheless a thoroughly coherent manual, in which the parts retain proper proportions to each other and to the whole. There are many statements in it which are now obsolete, or supplemented by more precise, fuller, or more accurate information. Groups not recognized by Woodward have attained their majority, and no longer train timidly in the leading-strings of a few bold specialists. The study of embryology, histology, and general anatomy, has entirely changed the situation so far as the point of view is concerned; but the great merits of Woodward, as originally published, are as conspicuous as ever. The work of Dr. Fischer is directly on Woodward's lines, and embodies of course much of his information; but it is not a mere revision, an ill-considered conglomeration like that of Tate, nor such a compilation as the present one of 'Tryon's. Silk and leather are good in their places; but man does not patch one with the other, or, doing so, repents of it. Mr. 'Tryon's first volume appears to us to resemble a mosaic of granite, chalk, precious stones, and mud, which is not delightful to the eye, neither will it wear. 'The work of the last twenty years in general, except so far as embodied in the ex- 